\title{
CRUSHING INJURIES TO THE SKULL : CLINICAL AND EXPERIMENTAL OBSERVATIONS
}

\author{
BY \\ W. RITCHIE RUSSELL and F. SCHILLER \\ From the Department of Neurology and the Accident Service, \\ Radcliffe Infirmary, Oxford
}

Severe crushing injuries of the head are often fatal, but in those patients who survive this form of injury the absence or slight degree of concussion is usually a striking feature of the clinical picture. Even though the skull may be fractured and the cranial nerves injured, the patient often remains fully conscious. This clinical observation led one of us (W.R.R.) with Denny-Brown (1941) to investigate experimentally the mechanism of cerebral concussion, and we found, as might be expected from clinical experience, that concussion is more readily produced by a blow when the head is free to move and not fixed. In most cases of accidental head injury the head is subjected to a sudden change of momentum which causes the shearing stresses in the brain which have been analysed by Holbourn (1943), and so brilliantly demonstrated experimentally by Pudenz and Shelden (1946). It seems clear that the common retention of consciousness with crushing injuries of the skull is due to the absence of any sudden change of momentum with an injury of this nature.

Compression of the skull beyond a certain degree will, however, cause loss of consciousness and brain damage by cerebral compression. The term compression concussion has been used to denote this form of injury (Denny-Brown and Russell, 1941).

\section{Case Records}

Case 1.-J. O'B., a miner, aged 49, was admitted to the Royal Infirmary, Edinburgh, on Jan. 1, 1933, shortly after an accident. He was working in a coal seam 26 inches high when a fall of rock pinned his head to the ground (lateral compression). $\mathrm{He}$ remained fully conscious but when released by other workers he was bleeding from the nose and right ear. When examined next day he was fully conscious, and there was little headache. There was a bruise in the left frontal region and extensive subconjunctival hæmorrhage in the right eye. He reported having swallowed a lot of blood from his nose : there was blood in the right ear and right facial weakness. Radiographs of the skull failed to $\overrightarrow{0}$ show a fracture. By Jan. 29, 1933, there was completeright facial paralysis and complete right sixth-nerves palsy. He was discharged home on Feb. 4, 1933. The? cranial nerve palsies recovered slowly, but on Dec. 24,5 . 1943 , he fell in an attack of vertigo and fractured the neck of his left femur. In February, 1935, his healthu was satisfactory, and he was planning to start light work.-

Case 2.-T. L., a railway carriage examiner, aged was admitted to the Royal Infirmary, Edinburgh, an July 24, 1933, after an accident in which his head 19d been crushed between two railway carriages. remembered all details of the accident and after releasse was able to walk for five minutes to a house. Therê was bleeding from the nose and both ears. He was conscious but very shocked on admission to hospian. 1. When examined on July 25,1933 , he was fully conscions but had severe headache and marked neck rigidity: The left pupil was larger than the right and there was complete left sixth-nerve paralysis. Radiological ex amination revealed a fissure fracture in the right fronto temporal region. On Aug. 1, 1933, the cerebrospina fluid pressure was $100 \mathrm{~mm}$. of water and the fluid was deeply blood-stained $(33,000$ red cells per c.mm.) and on standing the supernatant fluid was bright yellow $\overrightarrow{\vec{D}}$ The white cell count was 314 per c.mm. (15 per cent 3 polymorphs). Following lumbar puncture he had rigor and high fever at night for five days ; thereaftep he made a gradual recovery and was discharged home on Aug. 17, 1933.

Case 3.-A. C., a labourer, aged 43, had his head andं left leg pinned down by heavy oil drums sliding down. from a pile. He did not lose consciousness, and he said afterwards that he was most concerned with the immediate pain in his crushed leg, and he shouted for help to be released from the drums as he was unable to extricate himself. He was bleeding from his left ear which; from having a slight previous defect in hearing became completely deaf. There was a transient leftu sixth-nerve weakness and an almost complete left faciaP palsy which was still present one month after the accident Only special oblique radiograph showed a fracture o⿺ 


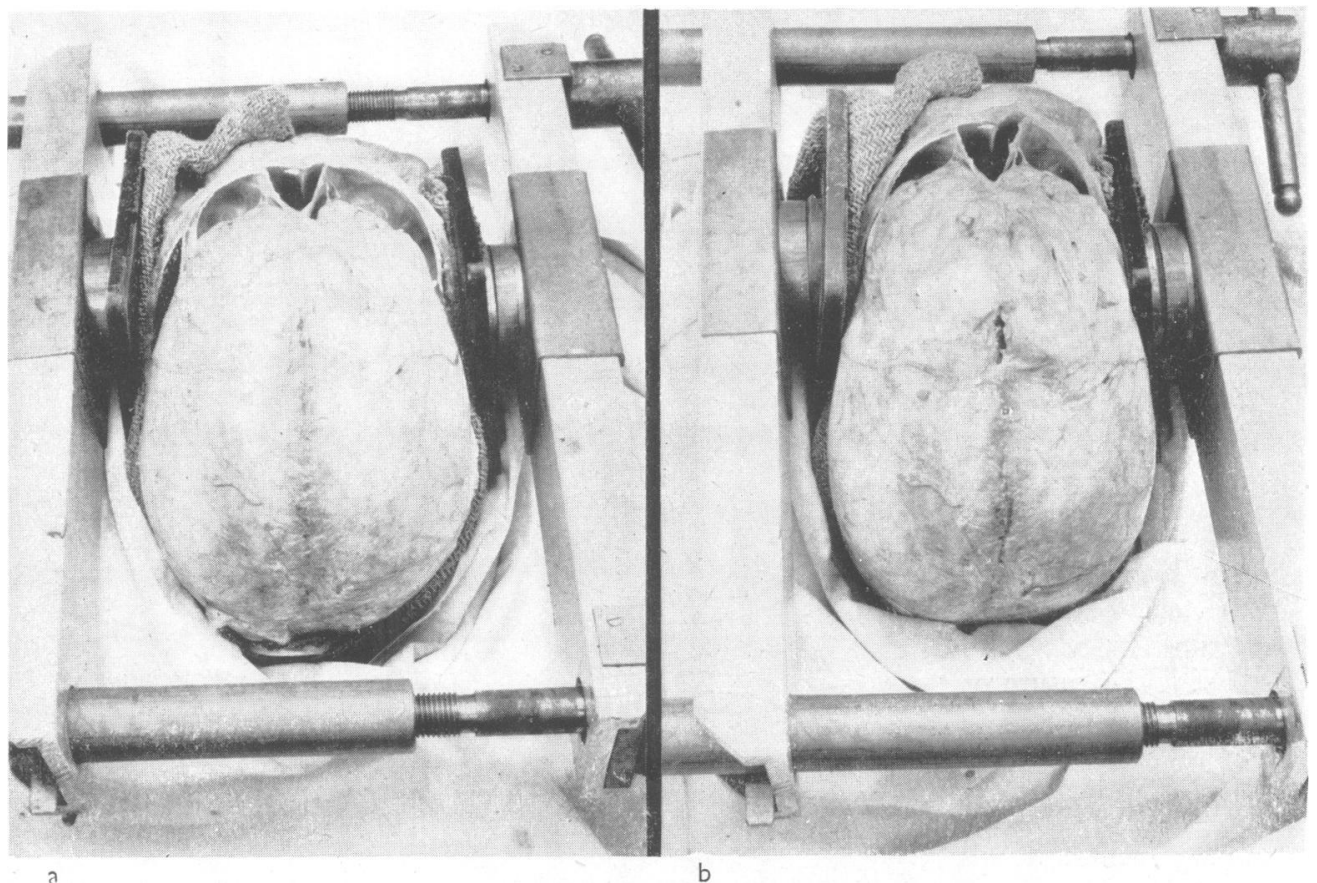

FIG. 1a.-The vice gripping the skull in a rather anterior transverse diameter, before applying pressure.

Fic. 1b.-Note bilateral narrowing and antero-posterior elongation of skull after crushing, and moderate deformity of brain (experiment VIII).

FiG. 2.-Transverse crush, rather oblique. Note typical avulsion of petrous bone, which has been forced medially and rotated backwards. Other fractures running into right orbital fissure and left posterior fossa (experiment IX). (The sides have been reversed by the camera.)

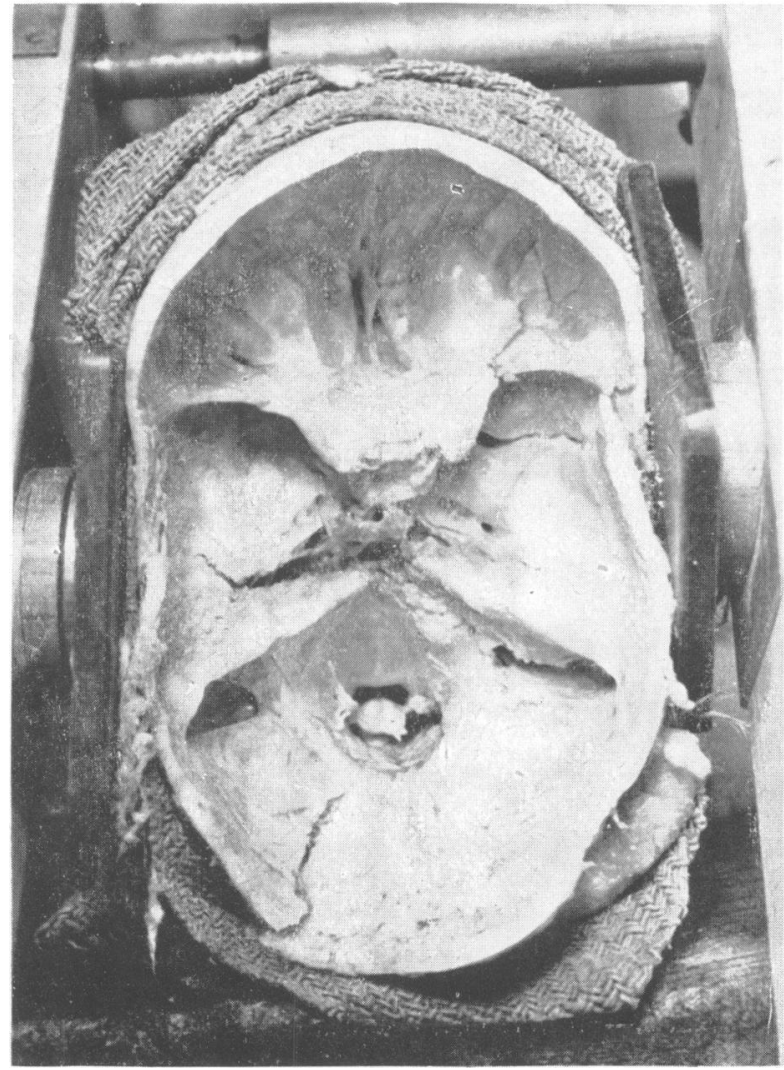



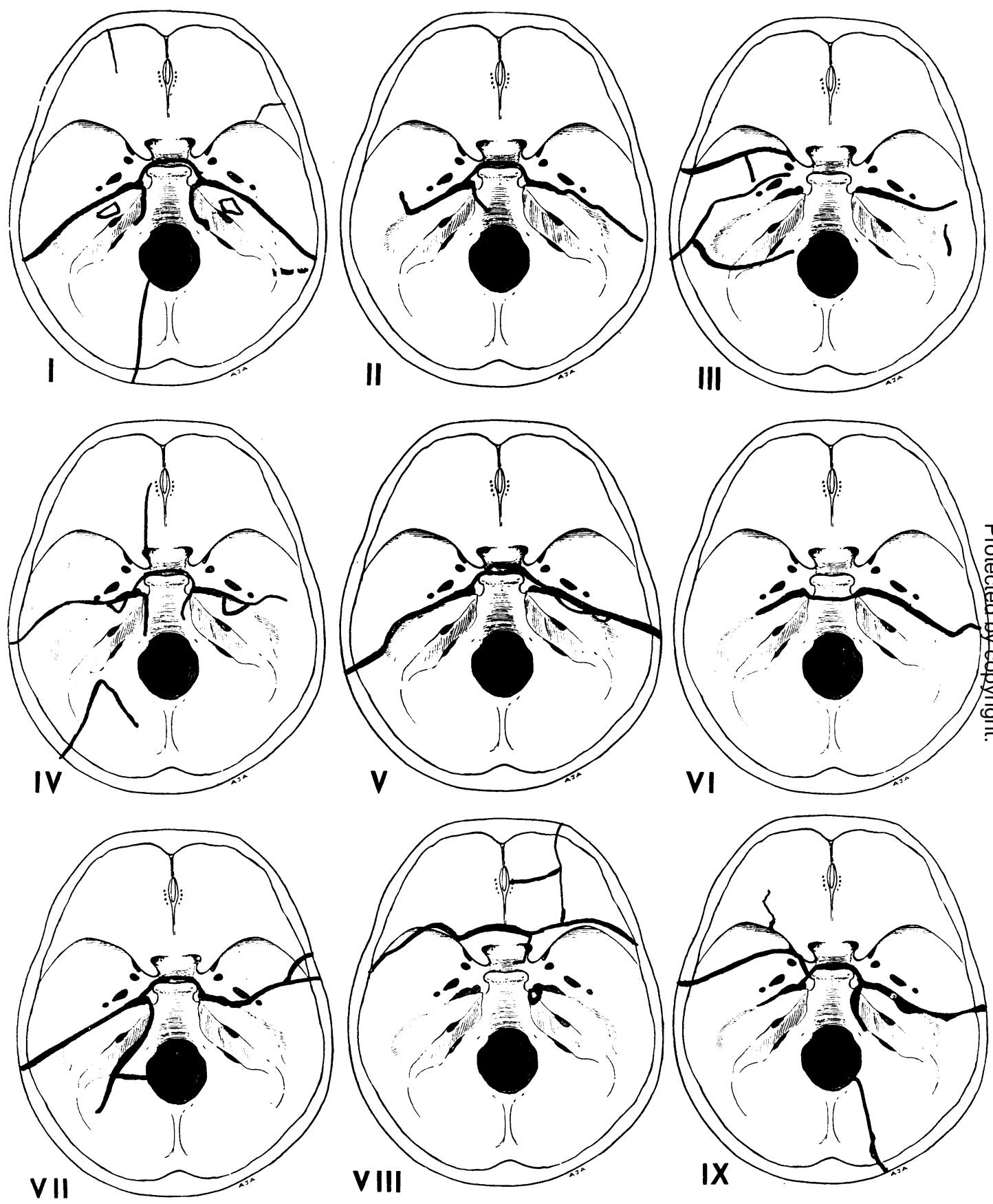

FIG. 3.-Fracture lines resulting from bilateral application of vice (experiments I to IX). 
FIG. 4.-Fracture lines resulting from antero-posterior application of vice (experiments $\mathrm{X}$ and $\mathrm{XI}$ ).
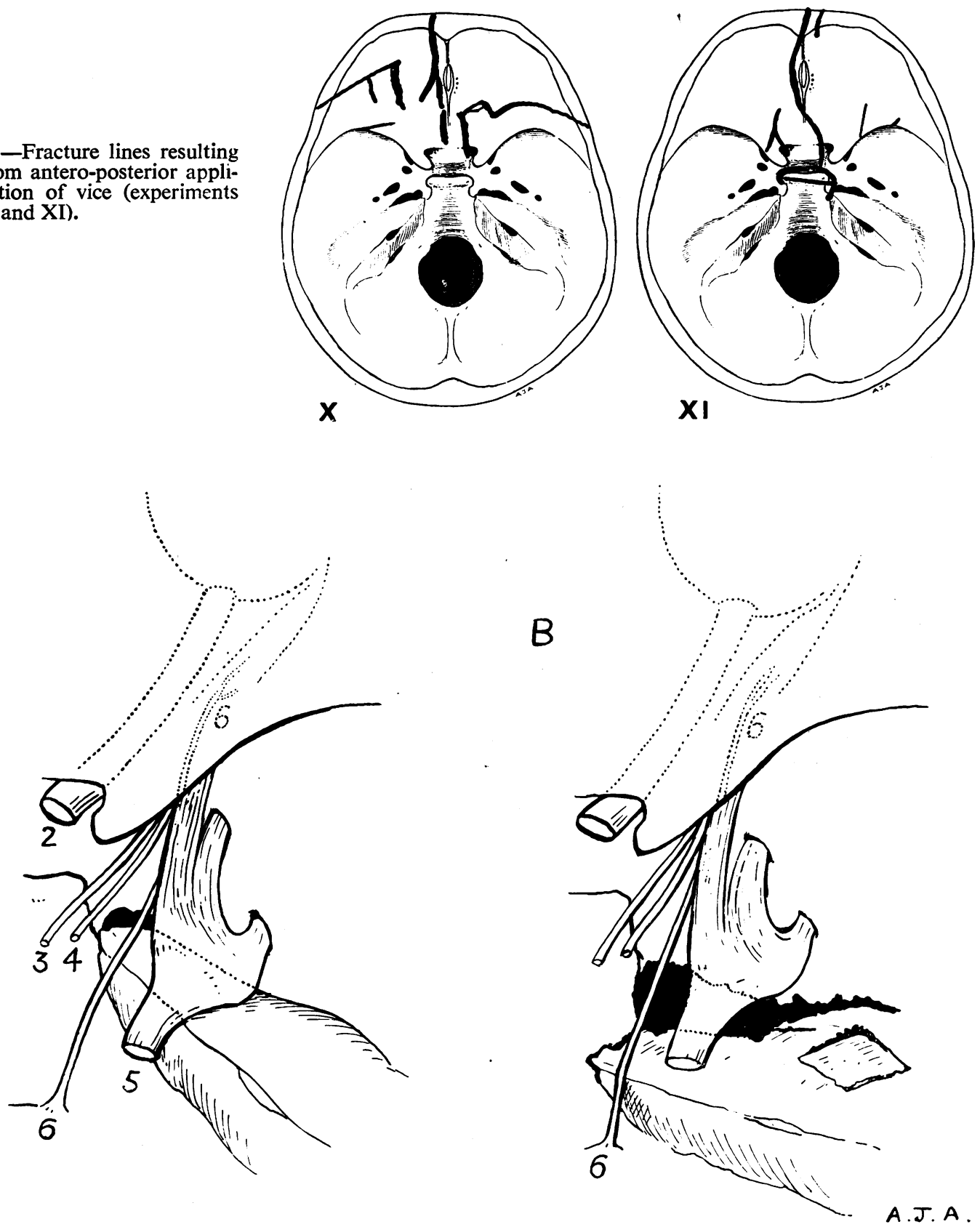

FIG. 5.-Schematic drawing of third, fourth, fifth, and sixth cranial nerves in relation to petrous apex, presuming that dura, cavernous sinus, internal carotid, artery, etc., have been dissected away.

(A) shows normal position, (B) stretching of sixth (and fifth) nerves across the gap, produced by crushing and avulsion of petrous bone ; the more medially placed third and fourth nerves remain intact. Note also the dislodged and fractured tegmen tympani. 


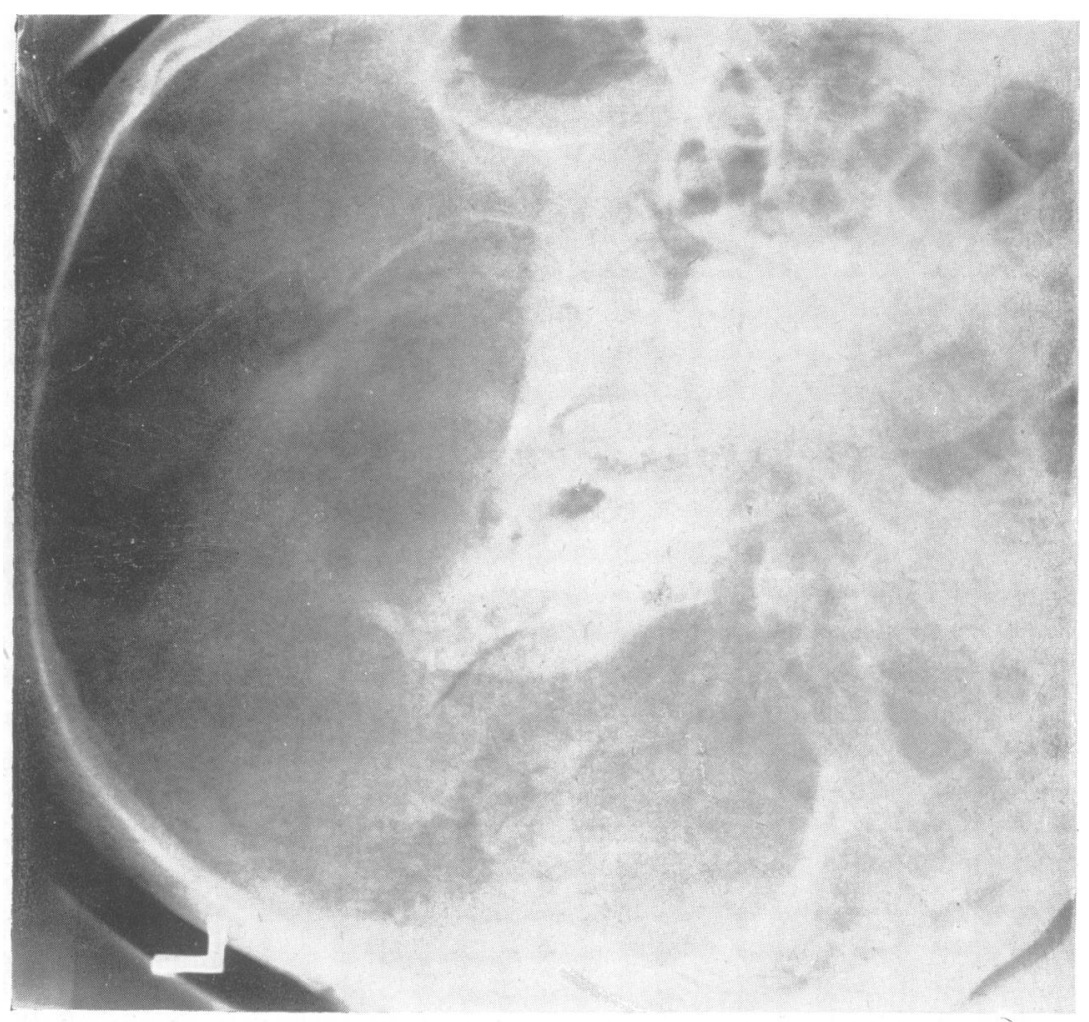

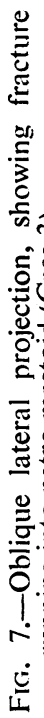


the left petrous bone involving the mastoid air cells (Fig. 7). The patient would have been able to resume work within three weeks, but for the fractured leg.

Case 4.-When 22 years of age J. R., a miner, was crushed between two hutches in the mine. He remembers all details of the injury and apparently the crush was bitemporal in direction. There was bleeding from both nostrils and the right ear. When examined seventeen years later (March 11, 1935) he was in fair health but had suffered from headaches at frequent intervals ever since the injury.

Case 5.-J. McN., aged 63, was admitted to the Royal Infirmary, Edinburgh, on Dec. 2, 1936, shortly after an accident. While he was standing between a motor lorry and a wall the lorry moved backwards and pinned his head against the wall. There was no loss of consciousness, and he remembers clearly the acute pain caused by the injury. Blood poured from his right ear, nose, and mouth. On the following day he developed complete left facial paralysis and there was slight deafness of both ears. There was effusion around the right eye with subconjunctival hæmorrhage. He had severe headaches for twenty-four hours. $X$-ray examination demonstrated a fracture in the right temporal bone.

He returned home on Jan. 5, 1937. When seen again on Sept. 6, 1937, he was free from symptoms and the facial paralysis had recovered.

Case 6.-W. G., a pit-boy, aged 15, was caught between two hutches in the mine on Oct. 11, 1937. Consciousness was not disturbed, and he was able to jump aside when the hutches separated. He remembers the severe pain of the crush, and blood poured from both ears and both nostrils. He was admitted to the Royal Infirmary, Edinburgh, the same day. There was pain in the head for a few days only, but radiographs revealed a vertical fracture involving the right parietal, squamous and petrous portions of the temporal bone. There was slight impairment of the sense of smell on the right side, and left facial weakness. He made a quick recovery, and when re-examined on Feb. 7, 1938, he felt quite fit.

Case 7.-J. T., a pit-boy, aged $14 \frac{1}{2}$ years, was crushed between hutches on Oct. 11, 1937. He remembers all details of the injury, but was reported to be dazed when admitted to the Royal Infirmary, Edinburgh, a few hours later. There was no $x$-ray evidence of fracture, but blood escaped from both ears and the nose. Five days later stereoscopic radiographs with the occipito-mental projection failed to show any fracture of the base of the skull. On Oct. 19, 1937, he was feeling fairly well but had diplopia. The left pupil was larger than the right, and reacted normally to light and convergence. The right pupil was inactive to light but contracted slightly on convergence. There was slight limitation of the outward movement of the left eye. On Jan. 5, 1938, the diplopia had recovered and the pupils were normal : he felt quite well and ready to resume work.

Case 8.-E. M., aged 29, while cycling was caught between two motor vehicles and his head was crushed.
So horrible did the accident look that he was reported dead in the evening paper of Sept. 29, 1947. But when admitted to the Radcliffe Infirmary, Oxford, he was found to be only moderately concussed, and he regained full consciousness a few hours after the accident.

There was bleeding from the left ear, bilateral deafness of a middle-ear type, bilateral external rectus and bilateral facial palsy, and complete anæsthesia and masticatory paralysis on the right side of the face. There was dysarthria and dysphagia, but no evidence of abnormality of the long cerebrospinal tracts. Radiographs showed a fracture running into the left middle fossa, and an ærocele filling the interpeduncular cisterna.

The hearing in both ears returned (with a scarred drum on the left side). The dysphagia subsided. But he remained somewhat dysarthric and much troubled by the lesions of the right fifth nerve and of both sixth and both seventh nerves.

Case 9.-Rfmn. P., aged 21, was on Dec. 6, 1941, crushed between an army lorry and a girder in a garage. He remembers the impact but nothing more for about twenty minutes, when he remembers being in an ambulance. On recovering consciousness he was found to have extreme dysarthria of a cerebellar type with ataxia of the limbs. The pupils were eccentric, being nearer the nasal edge of the cornea. They were also not quite circular, and there was marked hippus. No other abnormality was noted. $X$-ray examination revealed an extensive comminuted fracture of the left parietal bone, 10 by $5 \mathrm{~cm}$. in size. Eighteen months later his speech was still indistinct. He complained of headaches, irritability, and periods of depression. He had been obliged to give up several jobs.

Case 10.-Gnr. S., aged 29, was on Nov. 10, 1941, examining a gun tyre when the vehicle moved and passed over his head, pinning him to the ground. He remained fully conscious, but was unable to speak, and drummed the ground with his feet to attract attention. There was bleeding from the right nostril for an hour and some headache for twenty-four hours. In hospital he was found to have a complete ophthalmoplegia and blindness of the right eye, with anæsthesia in the distribution of the right supraorbital nerve. He remained fully conscious. The right clavicle was fractured.

$X$-ray examination revealed fractures of the roof of the right orbit, the right optic foramen, and of the greater wing of the sphenoid.

By April 30,1942, both the vision in the right eye and the ocular movements had recovered. The right pupil was, however, smaller than the left and inactive to light. As far as the head injury was concerned he had made a good recovery.

Case 11.-Gnr. A. F., aged 24, was on Feb. 11, 1941, travelling in a lorry when it overturned and he was crushed by $100-1 \mathrm{~b}$. shells it was conveying. Though there was no loss of consciousness and no amnesia, there was bleeding from the nose and weakness of the left sixth and seventh cranial nerves. The left pupil was 
smaller than the right and there was slight left deafness. He developed pulsating exophthalmos of the left eye, which was cured by ligation of the internal carotid artery first in the neck and later within the skull. Glaucoma of the left eye developed with complete loss of vision. $X$-ray examination failed to reveal any fracture. A year after the injury he was able to resume light manual work.

Case 12. -2/Lt. S., aged 20, had his head crushed below a Morris 8-h.p. motor car when the jack slipped. The rear axle pinned his head to the ground. He remained fully conscious while a friend lifted the car, and he was then able to get out and to stand up with blood pouring from his nose and right ear and from a cut on the left forehead. He noticed double vision while being taken to hospital. There was slight weakness of the right lateral rectus muscle, depression of the right corneal reflex, right facial paresis, and slight right deafness. Radiographs revealed a fissure fracture of the anterior part of the left squamous temporal bone which ran vertically upwards to the squamo-parietal junction, and downward into the base of the skull.

He made a good recovery and returned to duty two months after the injury.

Case 13.-Spr. S., aged 28, was on July 1, 1941, working under a truck when the jack slipped, and his head was pinned between the front axle and the ground. He was rendered deeply unconscious and had amnesia for fifteen days. There was bleeding from left parietal and right occipital wounds, but none from the nose or ears. The cerebrospinal fluid fourteen hours after the injury contained blood; the pressure was $180 \mathrm{~mm}$. of water. The right pupil was larger than the left, and the left arm and leg were slightly spastic with a left extensor plantar response.

$X$-ray examination revealed no fracture of the skull. Some weakness of the left side persisted, but he made a fair recovery and resumed light work nine months later.

Case 14.-Gnr. M., aged 30, was on May 6, 1942, caught between two heavy motor vehicles moving very slowly. He did not lose consciousness at any time, but a bolt on one of the vehicles caused a depressed fracture of the right temporal bone. This was operated on the same day : the dura was intact. There was also a cut in the left occipital region. The only abnormal physica 1 signs were nystagmus and the right pupil was larger than the left. He made a good recovery apart from some headaches reported on a follow-up report dated Oct. 13, 1943.

Case 15.-Pte. O.M., aged 20, overturned a truck he was driving on Feb. 26, 1942. While crawling out the truck settled on his head. There was no loss of consciousness or amnesia. Radiographs revealed a depressed fracture in the left parieto-temporal region.

He made a good recovery, and a year later was reported free from symptoms but serving a sentence in prison.

\section{Discussion of Clinical Cases}

The cause of the crushing injury in these fiftee cases was as follows :

Head caught between hutches

Head crushed by fall of rock in mine. .3

Crush between railway carriages $\quad \ldots$ 1

Crush between backing lorry and wall $\ldots 2 \quad 2$

Crush between 2 motor vehicles .. $\quad . .2$

Crush under axle of motor vehicle $\quad . .2$

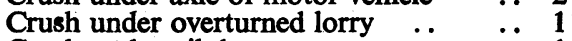

Crush under oil drums $\quad . . \quad \ldots$

Crush under several 100-1b. shells $\quad \ldots \quad . \quad 1$

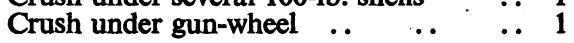

The signs of skull injury were :

$\begin{array}{lllll}X \text {-ray evidence of fracture } & & \ldots & \ldots & 10 \\ \begin{array}{l}\text { Bleeding from the ears } \\ \text { bilateral } \ldots\end{array} & \ldots & \ldots & \ldots & 9 \\ \text { Bleeding from the nose } & \ldots & \ldots & \ldots & 9\end{array}$

Fourteen of the fifteen cases showed clinical on $x$-ray evidence of skull fracture. Nevertheless the absence of concussion was a marked feature of mogt cases. Indeed all remained fully conscious without amnesia except three of the fifteen in which thefe was amnesia for twenty minutes, a few hours, 勒 fifteen days respectively.

All except three cases showed cranial nêrve involvement as follows :

\begin{tabular}{llll} 
Second cranial nerve & \multicolumn{2}{c}{ Cases } & 2 (one optic chiasm, \\
Fifth cranial nerve &.. & 3 (upper division) \\
Sixth cranial nerve &.. & 8 (bilateral in one) \\
Pupillary changes & $\ldots$ & 6 \\
Ophthalmoplegia &.. & 1 \\
Deafness .. &.. &.. & 5 (bilateral in two) \\
Dysarthria &.. &.. & 2
\end{tabular}

One patient developed a carotico-caverno窟 aneurysm, one a severe mid-brain syndrome, an one an ærocele. In two cases sub-arachnog d hæmorrhage was demonstrated.

The clinical features are therefore quite strikin $\overrightarrow{\mathrm{g}}$, for there is commonly clear evidence of fracture of the base of the skull and injury to cranial nerves without any of the loss of consciousness or concussion which so constantly accompanies the common forms of accidental head injury.

\section{Experimental Crush Injuries}

As the clinical features of crushing injuries showêd such considerable uniformity it was tempting investigate their mechanism by reproducing the deliberately in the post-mortem room. For this purpose a strong vice was used. It consisted of two parallel steel bars each carrying on a ball-and socket joint a sliding plate which could be applieg to the opposite sides of the skull. The steel bacss were joined together, and could be approximated 
by two transverse staffs bearing screws. This frame and vice could be applied in the bitemporal, oblique or antero-posterior diameters of the skull. The vice could be applied to the skull either while it was intact or after removal of the calvarium. In our experiments the pattern of fractures involving the base of the skull seemed to be the same whether the calvarium was removed or not.

Bilateral Crúsh.-With the vice applied to more or less symmetrical points in the temporal areas, the screws were tightened until the bone was heard to crack once or twice. Measurements showed that a transverse line drawn across the plane of the sella turcica in one experiment decreased by $11 \mathrm{~mm}$. when the first crack was heard, and by $24 \mathrm{~mm}$. with the second crack; the antero-posterior diameter being visibly lengthened. The brain appeared to be uninjured and only slightly deformed by this bilateral compression (Fig. 1).

The fractures through the base of the skull could be divided into those occurring regularly and others which were infrequent and inconstant. Three fairly constant main features were observed in the nine cases studied (Fig. 3).

1. In all cases unilateral or more usually bilateral fissures displaced the petrous bone from the great wing of the sphenoid, and from the squamous temporal bone along the petrosquamous fissure. The petrous bone was avulsed from its antero-lateral attachment by a rotatory movement around a vertical axis through the petrous base. The petrous apex travelled the greatest distance, in a backward and inward direction, thus .widening the foramen lacerum, and creating a large gap between the petrous and sphenoid (Fig. 2). The carotid canal and artery were thus laid bare. The fracture line usually ran postero-medially to the foramina ovale and spinosum, which were not commonly involved, nor were the acoustic or jugular foramina affected as a rule. In an oblique crush the foramen ovale was involved on one side, the jugular on the other. A small splinter was commonly broken off the tip of the petrous bones.

2. In half the cases the fracture also affected the thinnest part of the petrous temporal bone, that is, the tegmen tympani. In some instances this was neatly separated out as a diamondshaped plate (Fig. 3, experiments I, IV, V), thus unroofing the tympanic antrum and cavity. Bleeding from the ears was seen in two experiments, and rupture of the tympanic membranes on the one occasion when it was looked for (experiment $\mathrm{VI}$ ).
3. The fracture commonly extended across the dorsum of the sella turcica, linking up with its fellow which started at the opposite foramen lacerum. With sufficient pressure the base of the skull was actually broken in two, the parts articulating on a transverse hinge. In other words the principal fracture lines were found to run transversely, that is, in the direction of the compression.

Inconstant fractures were a fracture through the superior orbital fissure (experiments III and IX) which appeared before the usual petro-squamous lesion. A small crack of the orbital plate was the first fracture in experiment I. A fracture extending sagittally through one optic foramen and the frontoethmoidal fissure appeared in experiment IV. Fractures through the posterior fossa were seen only when excessive pressure had been applied (experiments I and IX); the foramen magnum was then bilaterally narrowed. Occasionally fractures appeared after a delay, while the vice was being kept in place without further tightening.

Antero-posterior Application of Vice.-Here again the effect of compressing the base of the skull was on the whole more one of tearing apart than of squeezing together. As the antero-posterior diameter was shortened and the lateral diameter lengthened, gaps appeared and widened in the cribriform plate, and indeed little else but the anterior fossa was affected. The most important fracture lines ran not perpendicular to, but in the direction of, the compressing force, that is, sagittally, and were apparently due to the anterior fossa being stretched from side to side. Thus the ethmoid sinuses were made to gape by a force that pulled them apart sideways and produced lines running from before backward; and the optic canals were split in the same direction (Fig. 4).

Transverse fractures may appear in the roofs of the orbits, and break off the dorsum sellæ: this may also be associated with chipping a flake off the petrous apex. In general, however, the middle fossa was practically unaffected in antero-posterior compression.

\section{Discussion}

\section{Mechanism of Injury to Cranial Nerves}

In transverse compression, the maximum distortion of the base of the skull takes place at the foramen lacerum, where, as has been seen, the avulsion of the petrous bone causes the petrous apex to rotate backwards and inwards. This must tend to stretch the sixth nerve as it runs across the increased gap of the foramen, and, together with the chipping off 
the petrous apex, affords an explanation for the common involvement of the abducent nerve in lateral crushing injuries. The same mechanism, namely the separation of the anterior part of the petrous bone from the greater wing of the sphenoid, implicates the fifth nerve. The ophthalmic division or the ganglion and roots suffer, either by the splitting and unroofing of the carotid canal, and the destruction of Meckel's cave, or because they are injured by stretching or tearing. It seems that the third and fourth nerve usually escape as they are not running across but medially to the petrous apex (Fig. 5). But they may be caught in fractures through the superior orbital fissure. Pupillary changes may be due to damage to the sympathetic network around the carotid in the foramen lacerum.

The damage to the facial nerve and to hearing is evidently of different origin : it is brought about by the fracture into the tympanic cavity. The deafness is usually of a middle-ear type and most patients recover from it; in the experiments the internal auditory meatus and probably the labyrinth remain intact. Damage to the middle ear explains both the hæmorrhage from the ear and the penetration of air into the cranial cavity.

In sagittal compression, with its effect on the ethmoidal and optic foramina, the olfactory and optic nerves are specially liable to suffer. In practice this form of crushing is probably much less common than the transverse type. In our clinical material Case 10 seems to have been affected in this way.

Duret (1919) in his classical monograph on head injuries has reached similar conclusions, which were based on experiments similar to ours in method and results, carried out by Hermann (1884), and by Patel near the end of the last century. He stressed in particular the role of the fractured petrous apex in producing the common sixth-nerve palsy (with or without involvement of the fifth), the fractures running parallel to the petrous axis, and his views are similar to our concept of the rotating petrous bone.

$X$-ray Examination.-In conclusion it should be emphasized that radiography often fails to demon. strate fractures of the base of the skull, especially where routine projections, including Towne's view, are used.

Fig. 6, for example, is the lateral radiograph of an experimentally crushed skull with large gaps between the petrous bones on one hand and the greater sphenoidal wing and the squamous temporal on the other (Fig. 3, experiment V). The crush w such as to produce bleeding from the ears in the cadaver and penetration of air into the basal cisterns, which is well shown on the radiograph. Yet the only radiographic evidence of bone damage is a fine, hardly perceptible fissure rising above to petrous bone.

It is therefore not surprising that in five out of ow fifteen patients fractures could not be demonstrated radiographically, although such clinical signs bleeding from the ears and cranial nerve palsies nearly all of them left little doubt as to the presence of basal fractures. As in these cases the temporal bone is usually affected, an oblique lateral projection is revealing in most instances; the tube is directed towards the lateral aspect of the skull at an angle of $35^{\circ}$ from the vertical, with the central ray pointing towards the feet (Fig. 7).

\section{Summary}

1. The records of fifteen cases of crushing infaity to the skull are given.

2. This type of injury, when the patient surviges, usually leads to no loss of consciousness, even though there is a fracture of the base of the \&\&1 and injury to cranial nerves. The absence of acceleration concussion presumably explains preservation of consciousness.

3. Crushing injuries were applied to the cadave and the pattern of basal fractures was fairly constaint in most experiments ; their bearing on the cliniogl picture is discussed.

4. The difficulty in demonstrating fractures of the base of the skull by radiograph was confirmed in these experiments.

We are particularly indebted to Dr. E. S. Schuster, O.B.E., who devised and constructed the vice used for the experimental studies, and to Dr. A.H.T. Robb-Smith and his staff for providing facilities in the post-mortem room.

\section{REFERENCES}

Denny-Brown, D., and Russell, W. R. (1941). Brain,

64,93. (1919). “" Traumatismes Cranio-Cérébraux Vol. 1, Part II, Paris, Alcan.

Holbourn, A. H. S. (1943). Lancet, 2, 438.

Pudenz, R. H., and Shelden, C. H. (1946). J. Neurgsurg., 3, 487. 